\title{
Interpreting Mamelodi Community-Oriented Primary Care data on tuberculosis loss to follow-up through the lens of intersectionality
}

\begin{tabular}{|c|c|}
\hline \multicolumn{2}{|c|}{$\begin{array}{l}\text { Authors: } \\
\text { Blandine B. Ilunga }^{1} \\
\text { Owen O. Eales }^{1} \\
\text { Tessa S. Marcus } \\
\text { Selma Smith } \\
\text { Jannie F. Hugo }^{1,2}\end{array}$} \\
\hline \multicolumn{2}{|c|}{$\begin{array}{l}\text { Affiliations: } \\
{ }^{1} \text { Department of Family } \\
\text { Medicine, School of } \\
\text { Medicine, Faculty of Health } \\
\text { Sciences, University of } \\
\text { Pretoria, Tshwane, } \\
\text { South Africa }\end{array}$} \\
\hline \multicolumn{2}{|c|}{$\begin{array}{l}{ }^{2} \text { Kalafong Provincial } \\
\text { Tertiary Hospital, Tshwane, } \\
\text { South Africa }\end{array}$} \\
\hline \multicolumn{2}{|c|}{$\begin{array}{l}\text { Corresponding author: } \\
\text { Owen Eales, } \\
\text { oweneales@gmail.com }\end{array}$} \\
\hline \multicolumn{2}{|c|}{$\begin{array}{l}\text { Dates: } \\
\text { Received: } 12 \text { Mar. } 2019 \\
\text { Accepted: } 22 \text { June } 2019 \\
\text { Published: } 04 \text { Feb. } 2020\end{array}$} \\
\hline \multicolumn{2}{|c|}{$\begin{array}{l}\text { How to cite this article: } \\
\text { Ilunga BB, Eales OO, } \\
\text { Marcus TS, Smith S, Hugo JF. } \\
\text { Interpreting Mamelodi } \\
\text { Community-Oriented Primary } \\
\text { Care data on tuberculosis loss } \\
\text { to follow-up through the lens } \\
\text { of intersectionality. Afr J Prm } \\
\text { Health Care Fam Med. } \\
\text { 2020;12(1), a2081. https:// } \\
\text { doi.org/10.4102/phcfm. } \\
\text { v12i1.2081 }\end{array}$} \\
\hline \multicolumn{2}{|c|}{$\begin{array}{l}\text { Copyright: } \\
\text { (c) 2020. The Authors. } \\
\text { Licensee: AOSIS. This work } \\
\text { is licensed under the } \\
\text { Creative Commons } \\
\text { Attribution License. }\end{array}$} \\
\hline \multicolumn{2}{|l|}{ Read online: } \\
\hline 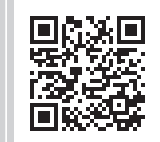 & $\begin{array}{l}\text { Scan this QR } \\
\text { code with your } \\
\text { smart phone or } \\
\text { mobile device } \\
\text { to read online. }\end{array}$ \\
\hline
\end{tabular}

Background: Tuberculosis (TB) is a persistent major public health challenge in South Africa. This article examines the social determinants and demographic factors associated with TB loss to follow-up through the lens of intersectionality.

Aim: The aim of this study was to describe and interpret the social determinants and demographic factors associated with TB patients lost to follow-up (LTFU).

Setting: Mamelodi, an urban settlement in the South African District of Tshwane.

Methods: AitaHealth ${ }^{\mathrm{TM}}$ is an Information and Communications Technology (ICT) mobile and web application that is used by community health workers. Data from patients with TB were extracted from the 64319 households registered on AitaHealth ${ }^{\mathrm{TM}}$ over a 3-year period. Univariate and multivariate analyses were used to compare patients who were adherent to TB treatment and those LTFU.

Results: Of the 184351 individuals screened for TB, 788 reported that they were diagnosed with TB (an incidence of 427 cases per 100000 ). Of the 704 eligible for inclusion in this analysis, $540(77 \%)$ were on treatment and 164 (23\%) were LTFU. The factors associated with LTFU were aged over 60, not having a South African identification document, migration and death in the household, and higher mean household income.

Conclusion: The results of this study serve as a reminder to clinicians of the importance of the three-stage assessment (biopsychosocial) in the approach to patients with TB. Understanding the intersection of social determinants and demographic factors helps clinicians and others identify and respond to the specificity of patient, health system and non-health policy issues at play in LTFU.

Keywords: Loss to Follow-Up; Tuberculosis; Social Determinants; Intersectionality; Community Health Workers; Community-Oriented Primary Care; eHealth.

\section{Introduction}

R. was a gardener and worked at two locations 6-7 days a week. He came from Malawi and had been living in South Africa for the last 7 years. He supported his girlfriend and also sent money to his children in Malawi.

In August 2018, he started coughing, losing weight and feeling weak. Apart from just hoping that he would soon get better, he did not seek medical help for a number of reasons. Firstly, he did not want to waste days of pay waiting all day at the clinic. Secondly, he did not feel that he could afford the expense of seeing a doctor, and finally he was afraid of losing his job and thus hid his medical problems from his employers.

Too weak to work, he finally went to the clinic where he was diagnosed with Tuberculosis (TB) and Human Immunodeficiency Virus (HIV). He did not accept the diagnosis. He believed that his symptoms were caused by bewitchment. After counselling at the local clinic as well as with extensive support and counselling from one of his employers, he agreed to take his medication. Because he had delayed treatment, his condition did not improve immediately. This fact fuelled his suspicion of bewitchment.

He worried about his livelihood. One employer stopped paying him. The other continued to support him without the expectation of him working. And because he was a foreign national, 
he did not have access to the temporary disability grant for severe TB that is afforded to South Africans.

He stopped taking his medication regularly and consulted with a traditional healer. His condition deteriorated, he struggled to walk and became disoriented. He died in January 2019.

South Africa has the world's sixth largest TB epidemic, ${ }^{1}$ with approximately $1 \%$ of the population developing active TB every year. ${ }^{2}$ It also has 7.2 million people living with HIV (2017) and an HIV prevalence of $18.9 \%$ (among people aged 15-49 years). ${ }^{3}$

Globally, TB has significantly complicated the HIV epidemic over the past two decades. ${ }^{4}$ It accounted for about one in four deaths of HIV-infected patients worldwide ${ }^{5}$ and more than half the deaths of people with HIV in South Africa, where an estimated $60 \%$ of HIV+ people have TB. Being HIV+ increases the risk of developing active TB 20- to $30-$ fold. ${ }^{6}$

Tuberculosis is a persistent and difficult condition to contain. The activation of TB and individual, institutional and system responses to it are the result of a complex interface of biological, social and environmental factors. These are structural, physical and social at the same time as they are embodied in individual and collective agency.

Existing understanding of the infectious agent Mycobacterium tuberculosis and the disease course it triggers has led to the development of effective prevention and treatment regimens even in a context of HIV and drug-resistant TB. Early treatment and treatment adherence lead to the restoration of patient health and at the same time helps control the spread of the disease. ${ }^{7}$ Isoniazid Preventive Therapy (IPT) significantly reduces the risk of TB activation in people infected with HIV and treatment. ${ }^{8}$ Testing helps prevent infection in families, communities and healthcare providers exposed to active TB. Conversely, treatment delay or interruption is a significant contributor to mortality and morbidity among TB patients and is an important cause of drug-resistant TB. ${ }^{9}$ In South Africa, nearly onethird of all diagnosed TB patients $(32.8 \%)$ are lost to followup (LTFU) in the existing facility-based healthcare system. Most are initial LTFU (27.2\%), where patients are diagnosed with TB but receive no treatment. ${ }^{2,10}$ The remaining $5.6 \%$ of all TB diagnosed patients LTFU is where patients have interrupted treatment for 2 or more months. ${ }^{2,11}$ Loss to follow-up outside of the clinical setting as contact tracing, screening and IPT initiation is often poorly implemented for adults, and especially for children, in South Africa and elsewhere. ${ }^{8}$

At a macro-level, TB transmission and treatment initiation, adherence and outcomes are generally associated with class, colour, origin, age and sex, as they manifest in income, education, occupation, shelter, food security, gender and marital status, migration and so on. ${ }^{12,13,14,15,16}$
However, it is difficult to translate these structural 'cause of causes' practically, either in the course of clinical care at an individual level or organisationally through the institutions of service delivery. There are several reasons for this. Social determinants fail to account for agency or the way people, individually and through institutions, act on the world even when they are constrained by the place, time and circumstances of their birth. ${ }^{17}$ Social structural causes fail to engage with the institutional arrangements that organise the distribution of services, resources and power. Conceptually, they are often construed as being hierarchically ordered in historically predetermined ways. ${ }^{18}$ And practically, they operate at a level of abstraction that is far removed from their embodiment in individuals and interpersonal relations. Simply put, they are difficult to distil to an out-of-context individual in a clinical encounter.

Gaps in knowledge and system responses evidenced by the failure to effectively contain the TB epidemic have seen some important paradigmatic and conceptual shifts. Significant basic science breakthroughs in HIV prevention and treatment have driven a paradigm shift in biophysical TB research. The global effort is now focused on the elucidation of biomarkers to 'accurately and promptly predict key active or latent TB. In much the same way that the identification of HIV viral load accurately predicts the development of opportunistic infections and mortality. ${ }^{\prime 19}$

Similarly, there have been shifts in society and system paradigms. Specifically, the notions of complex adaptive systems and, within them, intersectionality provide a way of accounting for the complexity of structure, system and agency in health and healthcare. ${ }^{18}$ Complex adaptive systems are made up of many parts that act on and react to each other in dynamic and evolutionary, non-linear ways. Intersectionality helps us consider simultaneity as it occurs in individuals and in the relations between individuals, or the co-occurrence and interaction of social determinants and systems that inform agency.

Institutionally, there is increasing awareness globally about the need to reconceptualise the healthcare system in a way that prioritises primary care and extends healthcare services to and from people in their homes and communities to achieve health for all. ${ }^{20}$ This is presently articulated in South Africa through the envisaged creation of a national health insurance to drive sector integration and costeffective, quality service delivery. ${ }^{21}$ Under the policy umbrella of primary care re-engineering, it has been practically developed and applied as 21st-century electronic Information and Communications Technology (ICT)enabled Community-Oriented Primary Care (COPC). Information and Communications Technology-enabled COPC mobilises clinical services and public health resources to deliver healthcare in the places where people live and work. It is geographically focused, person- and familycentred, comprehensive, generalist and equitable healthcare. It is delivered by multi-disciplinary teams, and informed 
by the best available practices and knowledge. It uses AitaHealth ${ }^{\mathrm{TM}}$, a web and mobile electronic platform that records, guides and reports healthcare information and services provided by health workers to individuals and families in their homes and communities. Purposively designed by the University of Pretoria and Mezzanineware/ Vodacom to enable real-time communication and datainformed decision support and service management, it is used by Ward-Based Outreach Teams (WBOTs) to register, assess and triage households and individuals according to national health disease and condition priorities, including TB. ${ }^{22}$

\section{Method \\ Study design}

A cross-sectional, descriptive analysis of demographic and social factors associated with TB treatment LTFU.

\section{Setting}

Mamelodi (Gauteng, South Africa) is a $45.2 \mathrm{~km}^{2}$ urban settlement in the east of the City of Tshwane. It has a population of 334577 people living in approximately 110703 households. Nearly all residents $(98.8 \%)$ are African and $42.5 \%$ speak Sepedi as the first language. One-third of the households are female headed and $40 \%$ live on less than R20 000 a year. The majority (61\%) of people reside in formal dwellings. About two-fifths (38.4\%) of the population above the age of 20 years have completed secondary school. ${ }^{23}$

\section{Selection and data collection}

The study population comprised 64319 registered households, with 184354 people who were screened for TB over the 3-year period, 01 August 2014-10 October 2017 (> $50 \%$ of the total Mamelodi population). All individuals, 18 years or older, captured on AitaHealth ${ }^{\mathrm{TM}}$ by community healthcare workers (CHWs), who were diagnosed with TB, were included in the study. Those who did not give consent for their data to be used for research purposes were excluded.

\section{Data analysis}

The following demographic and social factors were analysed, namely, age, sex, relationship status, possession of a South African Identification Document (ID), in- and out-migration, food security status, type of dwelling, ownership of the dwelling, death in the household and household income.

Data were cleaned and entries with contradictory information regarding treatment status were excluded. Cleaned data were then grouped into two, namely, TB treatment adherent and LTFU. The data were analysed using EpiData software. Groups were compared using Fisher's exact test at the 0.05 level of significance. Odds Ratios (ORs) for all factors were reported along with a 95\% Confidence Interval (CI). Informed consent was obtained on AitaHealth ${ }^{\mathrm{TM}}$ for both service and research.

\section{Ethical considerations}

Ethical approval for the study was obtained from the Faculty of Health Sciences Research Ethics Committee of the University of Pretoria (Ethics reference number: 286/2018).

\section{Results}

Of the 184351 individuals screened for TB, 788 reported that they were diagnosed with TB. This equates to an incidence of 427 cases per 100000 population over the 3-year period. Respondents below 18 years of age (84) were excluded. Of the 704 eligible for inclusion in this analysis, 540 (77\%) were on treatment and $164(23 \%)$ were LTFU.

Most (58\%) of the respondents were male, single (68\%) and of formal working age (18-59) (89\%). Sixty-one per cent were foreigners and did not have a South African ID document (Table 1).

Most (83\%) of the respondents lived in dwellings owned by them or their families, although only 59\% lived in formal houses. While few households $(n=23,4 \%)$ had experienced in-migration of a household member, nearly three times as many $(n=62,9 \%)$ had experienced out-migration in the

\begin{tabular}{|c|c|c|}
\hline \multirow[t]{2}{*}{ Characteristics } & \multicolumn{2}{|c|}{$\begin{array}{c}\text { Number of participant } \\
\qquad n=704\end{array}$} \\
\hline & $N$ & $\%$ \\
\hline \multicolumn{3}{|l|}{ Age $(n=693)$} \\
\hline $18-40$ years & 326 & 47 \\
\hline$>40-60$ years & 297 & 43 \\
\hline$>60$ years & 70 & 10 \\
\hline \multicolumn{3}{|l|}{$\operatorname{Sex}(n=704)$} \\
\hline Male & 408 & 58 \\
\hline Female & 296 & 42 \\
\hline \multicolumn{3}{|l|}{ Possession of RSA ID ( $n=704)$} \\
\hline Possess & 272 & 39 \\
\hline Does not possess & 432 & 61 \\
\hline \multicolumn{3}{|c|}{ In-migration in last 12 months ( $n=615)$} \\
\hline No & 592 & 96 \\
\hline Yes & 23 & 4 \\
\hline \multicolumn{3}{|c|}{ Out-migration in last 12 months ( $n=691)$} \\
\hline No & 629 & 91 \\
\hline Yes & 62 & 9 \\
\hline \multicolumn{3}{|l|}{ Food security $(n=628)$} \\
\hline Food security & 527 & 84 \\
\hline Food insecurity & 101 & 16 \\
\hline \multicolumn{3}{|l|}{ Dwelling type $(n=621)$} \\
\hline House & 365 & 59 \\
\hline Shack & 208 & 33 \\
\hline Room & 48 & 8 \\
\hline \multicolumn{3}{|c|}{ Ownership of dwelling ( $n=690)$} \\
\hline Own the dwelling & 573 & 83 \\
\hline Do not own the dwelling & 117 & 17 \\
\hline \multicolumn{3}{|c|}{ Death in the household ( $n=691)$} \\
\hline No death within 12 months & 599 & 87 \\
\hline Death within 12 months & 92 & 13 \\
\hline \multicolumn{3}{|l|}{ Groups $(N=704)$} \\
\hline Adherent to treatment & 540 & 77 \\
\hline LTFU & 164 & 23 \\
\hline
\end{tabular}

ID, identification document; LTFU, lost to follow-up. 
TABLE 2: A comparison of selected socio-demographic characteristics of people with tuberculosis in treatment and lost to follow-up.

\begin{tabular}{|c|c|c|c|c|c|c|c|c|}
\hline \multirow[t]{2}{*}{ Exposure variables } & \multicolumn{2}{|c|}{ In treatment } & \multicolumn{2}{|c|}{ LTFU } & \multicolumn{2}{|c|}{ Univariate analysis } & \multicolumn{2}{|c|}{ Multivariate analysis } \\
\hline & $n$ & $\%$ & $n$ & $\%$ & Crude OR & $p$ & Adjusted OR & $p$ \\
\hline \multicolumn{9}{|l|}{ Age $(n=693)$} \\
\hline $18-40$ years & $243 / 532$ & 46.0 & $83 / 161$ & 52.0 & 1.00 & - & 1.00 & - \\
\hline$>40-60$ years & $245 / 532$ & 46.0 & $52 / 161$ & 32.0 & 0.62 & 0.017 & 0.75 & 0.220 \\
\hline$>60$ years & $44 / 532$ & 8.0 & $26 / 161$ & 16.0 & 1.70 & 0.045 & 2.04 & 0.031 \\
\hline \multicolumn{9}{|c|}{ Possession of South African ID $(n=704)$} \\
\hline Possess & $229 / 540$ & 42.4 & $43 / 164$ & 26.2 & 1.00 & - & 1.00 & - \\
\hline Not possess & $311 / 540$ & 57.6 & $121 / 164$ & 73.8 & 2.07 & $<0.001$ & 2.30 & 0.021 \\
\hline \multicolumn{9}{|c|}{ In-migration within last 12 months $(n=616)$} \\
\hline No & $476 / 485$ & 98.1 & $116 / 130$ & 89.2 & 1.00 & - & 1.00 & - \\
\hline Yes & $9 / 485$ & 1.9 & $14 / 130$ & 10.8 & 6.38 & $<0.001$ & 3.12 & 0.022 \\
\hline \multicolumn{9}{|c|}{ Out-migration within last 12 months $(n=691)$} \\
\hline No & $506 / 535$ & 94.6 & $123 / 156$ & 78.8 & 1.00 & - & 1.00 & - \\
\hline Yes & $29 / 535$ & 5.4 & $33 / 156$ & 21.2 & 4.68 & $<0.001$ & 2.75 & 0.006 \\
\hline No death & $485 / 535$ & 90.6 & $114 / 156$ & 73.1 & 1.00 & - & 1.00 & - \\
\hline Death & $50 / 535$ & 9.4 & $42 / 156$ & 26.9 & 3.70 & $<0.001$ & 1.83 & 0.058 \\
\hline
\end{tabular}

Note: Bold values indicate $p<0.05$ as significant or between 0.05 and 0.01 as marginally significant.

$\mathrm{OR}$, odds ratio; ID, identification document; LTFU, lost to follow-up.

previous 12 months. Sixteen per cent were food insecure and $13 \%$ had experienced a death in the household within the previous 12 months. The median household income was R2000 per month in the 161 (23\%) individuals who reported on this item.

Univariate and multivariate comparison of the sociodemographic characteristics of individuals who are TB treatment adherent and those LTFU found several important differences (see Table 1).

People who did not possess a South African ID were twice as likely to be LTFU compared with those who possessed. Also, individuals with TB were three times more likely to be LTFU where there had been a death in the household (Table 2).

Comparing income data, available for 32\% (53/164) of the LTFU group and 20\% (109/540) of the treatment adherent group, the median income of those who were LTFU (R3000) was $50 \%$ more than those who adhered to TB treatment (R2000).

In multivariate analysis, not possessing a South African ID $(p=0.015)$, a death in the household $(p=0.015)$ and outmigration, where a household member left the household in the previous 12 months ( $p=0.012$ ), were found to be significantly associated with LTFU.

\section{Discussion}

This study found a TB incidence of 427 per 100000 over the 3-year period, which is lower than the 2017 WHO South Africa TB estimate of 567 per $100000^{24}$ (WHO TB burden estimates). Although not strictly comparable in terms of timeframe, it is likely that the prime reason for the difference in incidence in this geographic community compared to the country as a whole is that the total population data conceal local variability and the importance of place. It is well known that the incidence of many conditions varies by locality. For example, even in a generalised HIV epidemic where TB is the primary opportunist infection, the TB incidence in Southern Africa is higher in mining and mining labour-supply communities compared to those where people are not involved in mineral extraction. ${ }^{25}$

What these locality-specific data collected by $\mathrm{CHW}$ doing IT-enabled COPC provide is an understanding of micro-level incidence. Not only is such information generally not available, it is also not usually linked in real time to a healthcare service that extends delivery to and from homes. Using AitaHealth ${ }^{\mathrm{TM}}$, healthcare professionals and workers involved in community-based and facility primary healthcare are able to access person- and patient-specific data to inform prevention and treatment practice in context.

The definition of LTFU with respect to TB is either being diagnosed but not starting treatment (also called initial LTFU) or once initiated, interrupting treatment for 2 or more consecutive months (formerly termed treatment defaulters). ${ }^{11}$ In this study, nearly a quarter $(23 \%)$ of TB diagnosed patients were LTFU, which is high, even though it is lower than the national estimate of $32.8 \%$. The official percentage of LTFU is $5.6 \%$, but if we include the initial LTFU at $27.2 \%,{ }^{10}$ the percentage increases to $32.8 \%$ or nearly one-third of all diagnosed TB patients.

Similar to international research, the results of this study show that age, particularly being older ( $>60$ years), is associated with LTFU. However, no association was found between sex and TB LTFU, contrary to other evidence of clear significant associations between being male and defaulting TB treatment. ${ }^{26,27}$

Two of the commonly known socio-economic drivers of TB LTFU were found in this study. Loss to follow-up was significantly associated with the migration of a household 
member out of the area within the previous 12 months as was being foreign or without having a South African ID. The pull and push for internal and international migration is most often related to the pursuit of economic opportunities and/ or the escape of war, conflict and political as well as domestic repression. Inevitably migration also results in the disruption and loss of structural and emotional support systems and at the same time as it engenders the necessity of negotiating unfamiliar, sometimes hostile cultural and institutional environments. ${ }^{28}$ There is strong evidence that people without South African IDs and internal migrants living in urban peripheries face documentation, language and service access barriers to healthcare ${ }^{29}$ as well as discriminatory and disrespectful in-facility care. ${ }^{30}$

The finding that death in the household in the preceding 12 months is marginally associated with LTFU $(p=0.058)$ speaks about two dimensions of the challenge of treating TB, namely, one relates to the importance of the family in treatment adherence, ${ }^{31}$ especially the role of lack of social support in negative treatment outcomes, ${ }^{32}$ and the other relates to the infectious nature of TB that puts all household members at risk of infection and death. Debilitated by TB, the association of death and TB in a household impacts people's sense of self-worth and self-efficacy, as well as their interpersonal relations, especially the ability and desire of others to support them through their illness, including starting and staying on treatment. ${ }^{33}$

Contrary to expectation, the LTFU group had a higher mean household income (R3000) than those in the adherent group (R2000). It would seem that in a context of relative poverty, a risk to LTFU is the struggle to keep income and resist descent into greater poverty. Although this finding needs to be treated with some caution as it is based on only a subset of respondents, it is consistent with other studies that have shown that TB worsens poverty because of loss of income incurred in seeking healthcare and that this loss is greatest in the period prior to starting treatment. ${ }^{34}$

While each of these socio-economic and demographic factors provides insights into the structural determinants that underlie LTFU, it is in their intersection that their impact becomes significant. Intersectionality helps frame the relationship between factors in a way that is meaningful and practical. In this specific context, LTFU was found at the intersection of being physically, socially and institutionally 'out of place' (migrant, foreign) and a part of the relatively better-off poor. Intersectionality also talks about the fact that determinants are embodied in individuals and in the power relationships between people. They inform agency or what people think and feel they can do about conditions and circumstances, be they patients, healthcare practitioners, family, friends and community members. This makes the concept of intersectionality practically useful because it links the understanding of health determinants to the complexity of people's responses at the micro-level as well as to their relationships at meso- and macro-levels.

\section{Conclusion}

The coalface of healthcare, including TB LTFU and other impediments to treatment, is constituted and reconstituted by the intersections of multi-dimensional, socially embodied people in relationship to themselves and others in time and place.

For clinicians practising patient-centred care, this study shows that understanding intersectionality is key to doing effective three-stage (biopsychosocial) assessments ${ }^{35}$ and developing mutually agreed plans that actually mobilise people's ability to make choices.

For healthcare service managers, the study shows that health responses and outcomes are shaped by the intersection of systems and people in their homes and communities. To get ahead of the TB epidemic, it is essential to create a coordinated comprehensive system that could provide services to people to and from the home and facilities in ways that support equity.

For policymakers, the study shows how societal and policy issues that extend beyond the direct remit of health systems directly and negatively impact efforts to contain TB. Healthfor-all means ensuring that all sectors and services are aligned to protect the vulnerable and the weak.

\section{Strengths and limitations Strengths}

The data were captured electronically and referenced to a GPS coordinate. The data were captured over a 3-year period and thus were not influenced by seasonal fluctuations in LTFU. The data were collected at household level by CHWs. This study included all initial LTFU data (patients diagnosed with TB but not initiated on TB treatment).

\section{Limitations}

The questions that informed LTFU in this study are not exactly the same as the official WHO definition. We asked about household members who have been diagnosed with TB in the last 12 months and have defaulted or stopped TB treatment. The 2013 WHO definition of LTFU is as follows, namely, a TB patient who has interrupted or stopped TB treatment for more than 2 months. This definitional difference may account for some of the variations between site-specific and national incidence. The data were captured by $\mathrm{CHWs}$ with different experience and training, which could influence data quality. The data only show an association with LTFU and causality cannot be inferred. Household data used in this study are self-reported and may be influenced by difficulty in recall and response bias. ${ }^{36}$

\section{Acknowledgements}

The authors would like to thank P. Mahuma (Family Physician, Department of Family Medicine, University of Pretoria), 
J.B. Ikombele (Family Physician, Mamelodi Hospital) and T. Bongongo (Family Physician, Sefako Makgato University) for their assistance with the original study; Leroux Engelbrecht (Wellnicity) for data extraction; Prof. J. Becker (Faculty of Health Sciences, University of Pretoria) for statistical analysis; Nicoleen Smit, (Research Technician, Department of Family Medicine, University of Pretoria) for the manuscript preparation; and the patient J.L. (1984-2018).

\section{Competing interests}

The authors declare that they have no financial or personal relationships that may have inappropriately influenced them in writing this article.

\section{Authors' contributions}

B.B.I., O.O.E. and S.S. were responsible for the conceptualisation of the study design and data analysis. T.S.M. and O.O.E. were responsible for the interpretation framework. O.O.E., TS.M., J.F.H. and S.S. were responsible for the discussion and critical review.

\section{Funding information}

No funding was received for the preparation of this article.

\section{Data availability statement}

Data sharing is not applicable to this article as no new data were created or analysed in this study.

\section{Disclaimer}

The views expressed in this article are the authors' own and not the official position of the University of Pretoria.

\section{References}

1. South Africa National AIDS Council. Let our actions count: South Africa's Nationa Strategic Plan for HIV, TB and STIs 2017-2022 [homepage on the Internet]. c2017 [updated 2017 May 11; cited 2019 Feb 15]. Available from: http://www.hst.org. za/publications/NonHST\%20Publications/NSP\%202017-SUMMARY.pdf.

2. Massyn N, Peer N, English R, Padarath A, Barron P, Day C. Editors. District Health Barometer 2015/16 [homepage on the Internet]. Health Systems Trust; c2016 [updated 2016 Jan 10; cited 2019 Feb 27]. Available from: http://www.hst.org. $\mathrm{za} /$ publications/District $\% 2 \mathrm{OHealth} \% 2 \mathrm{OB}$ arometers/District $\% 20 \mathrm{Health} \% 2 \mathrm{O}$ Barometer\%202015_16.pdf.

3. Avert. HIV and AIDS in South Africa [homepage on the Internet]. c 2018 [updated 2019 Jan 18; cited 2019 Jan 7]. Available from: https://www.avert.org/ professionals/hiv-around-world/sub-saharan-africa/south-africa.

4. Swaminathan S. Tuberculosis/HIV co-infection. Int J Infect Dis. 2016;45(Suppl 1):6. https://doi.org/10.1016/j.ijid.2016.02.043

5. Fielder J. Tuberculosis in the era of HIV: A clinical manual for care providers working in Africa and other resource-limited settings. Pretoria: USAID/PEPFAR/ FPD10; 2010.

6. WHO. Tuberculosis [homepage on the Internet]. c2018 [updated 2018 Sept 18; cited 2019 Jan 7]. Available from: https://www.who.int/news-room/fact-sheets/ detail/tuberculosis.

7. National Department of Health. National tuberculosis management guidelines. Pretoria: National Department of Health; 2014.

8. Black F, Amien F, Shea J. An assessment of the isoniazid preventive therapy programme for children in a busy primary healthcare clinic in Nelson Mandela Bay Health District, Eastern Cape Province, South Africa. S Afr Med J. 2018;108(3):217-223. https://doi.org/10.7196/SAMJ.2018.v108i3.12639

9. Caminero JA. Multidrug-resistant tuberculosis: Epidemiology, risk factors and case finding. Int J Tuberc Lung Dis. 2010;14(4):382-390.

10. Massyn N, Padarath A, Peer N, Day C. District health barometer 2016/17. Durban: Health SystemsTrust; 2017, p. 142.
11. World Health Organization. Global tuberculosis report 2013. WHO/HTM/ TB/2013.11 [homepage on the Internet]. c2018 [updated 2019 Feb 28; cited 2019 Jan 7]. Available from: https://www.who.int/tb/publications/global_report/en/.

12. Tola HH, Tol A, Shojaeizadeh D, Garmaroudi G. Tuberculosis treatment nonadherence and lost to follow up among TB patients with or without HIV in developing countries: A systematic review. Iran J Public Health. 2015;44(1);1-11.

13. Kigozi G, Heunis $C$, Chikobvu $P$, Botha $S$, Van Rensburg D. Factors influencing treatment default among tuberculosis patients in a high burden province of South Africa. Int J Infect Dis. 2017;54(C):95-102. https://doi.org/10.1016/j. ijid.2016.11.407

14. Muture BN, Keraka MN, Kimuu PK, Kabiru EW, Ombeka VO, Oguya F. Factors associated with default from treatment among tuberculosis patients in Nairob province, Kenya: A case control study. BMC Public Health. 2011;11:696. https:// doi.org/10.1186/1471-2458-11-696

15. Liew SM, Khoo EM, Ho BK, et al. Tuberculosis in Malaysia: Predictors of treatment outcomes in a national registry. Int J Tuberc Lung Dis. 2015;19(7):764-771. https://doi.org/10.5588/ijtld.14.0767

16. De Seixas Maciel EMG, Amancio JdS, De Castro DB, Braga JU. Social determinants of pulmonary tuberculosis treatment non-adherence in Rio de Janeiro, Brazil. PLoS One. 2018;13(1):e0190578. https://doi.org/10.1371/journal.pone.0190578

17. Scambler G. Resistance in unjust times: Archer, structured agency and the sociology of health inequalities. Sociology. 47(1):142-156. https://doi. org/10.1177/0038038512455878

18. McGibbon E, McPherson C. Applying intersectionality \& complexity theory to address the social determinants of women's health. Women's Health Urban Life. 2011;10(1):59-86

19. Hamilton CD, Swaminathan S, Christopher DJ, et al. RePORT International: Advancing tuberculosis biomarker research through global collaboration. Clin Infect Dis. 2015;61(Suppl 3):S155-S159. https://doi.org/10.1093/cid/civ611

20. Campbell J, Admasu K, Soucat A, Tlou S. Maximizing the impact of communitybased practitioners in the quest for universal health coverage. Bull World Health Organ. 2015;93(9):590-590A. https://doi.org/10.2471/BLT.15.162198

21. National Department of Health (NDOH), Republic of South Africa. White Paper for the transformation of the health system in South Africa [homepage on the Internet]. c1997 [updated 2008 Apr 23; cited 2012 Aug 14]. Available from: http:// www.info.gov.za/whitepapers/1997/health.htm.

22. Bam N, Marcus T, Hugo J, Kinkel H-F. Conceptualizing community oriented primary care (COPC) - The Tshwane, South Africa, health post model. Afr J Prim Health Care Fam Med. 2013;5(1):a423. https://doi.org/10.4102/phcfm.v5i1.423

23. Statistics South Africa. South African National Census of 2011: Statistical release [homepage on the Internet]. c2011 [updated 2015; cited 2017 Nov 28]. Available from: http://www.statssa.gov.za/?page_id=1021\&id=city-of-tshwaneAvailable from:
municipality.

24. World Health Organization. TB burden estimates and country-reported TB data [homepage on the Internet]. c2018 [2019 Jan 20; cited 2019 Jan 7]. Available from: https://extranet.who.int/sree/Reports?op=Replet\&name=\%2FWHO_HQ_Reports
$\% 2$ FG2 $\% 2$ FPROD $\% 2$ FEXT\%2FTBCountryProfile\&ISO2=ZA\&LAN=EN\&outtype=html.

25. TIMS. TB in the mining sector in Southern Africa. Report of the Dissemination Workshop for the Evidence Generating Studies Conducted under the TIMS Gran [homepage on the Internet]; 2017 May 10-11. Southern Sun Hotel, Johannesburg. [homepage on the Internet]; 2017 May 10-11; Southern Sun Hotel, Johannesburg. Workshop\%20-\%20Final\%20Report.pdf.

26. Basa S, Venkatesh S. Study on default and its factors associated among tuberculosis patients treated under DOTs in Mayurbhanj district, Odisha. J Health Res Rev. 2015;2(1):25-28. https://doi.org/10.4103/2394-2010.158125

27. Da Silva V, Tigeh S, Wirawan N, Bakta M. The relationship between education, job and family income with TB dropouts inTimor-Leste. Bali Med J. 2016;5(2):97-100. https://doi.org/10.15562/bmj.v5i2.223

28. Dhavan P, Dias HM, Creswell J, Weill D. An overview of tuberculosis and migration. Int J Tuberc Lung Dis. 2017;21(6):610-623. https://doi.org/10.5588/ijtld.16.0917

29. Veareyi J, Modisenyane M, Hunter-Adamsiv J. Towards a migration-aware health system in South Africa: A strategic opportunity to address health inequity. S Afr Health Rev. 2017;1:89-98.

30. Oosthuizen SJ, Bergh AM, Pattinson RC, Grimbeek J. It does matter where you come from: Mothers' experiences of childbirth in midwife obstetric units, Tshwane, South Africa. Reprod Health. 2017;14(1):151. https://doi.org/10.1186/ Tshwane, South Africa.
s12978-017-0411-5

31. GuqssaBoru C, Shimels T, Bilal Al. Factors contributing to non-adherence with treatment among TB patients in Sodo Woreda, Gurage Zone, Southern Ethiopia: A qualitative study. J Infect Public Health. 2017:10(5):527-533. https://doi. org/10.1186/s12978-017-0411-5

32. Mburu G, Restoy E, Kibuchi E, Holland P, Harries AD. Detention of people lost to follow up on TB treatment in Kenya: The need for human rights-based alternatives. Health Hum Rights. 2016;18(1):43-54.

33. Grede N, Claros JM, De Pee S, Bloem M. Is there a need to mitigate the social and financial consequences of tuberculosis at the individual and household level? AIDS Behav. 2014;18(Suppl 5):S542-S553. https://doi.org/10.1007/s10461-0140732-0

34. Foster N, Vassall A, Cleary S, Cunnama L, Churchyard G, Sinanovic E. The economic burden of TB diagnosis and treatment in South Africa. Soc Sci Med. 2015;130(2015):42-50. https://doi.org/10.1016/j.socscimed.2015.01.046

35. Van Rooyen MR, Hugo J, Louw JM. The consultation. In: Mash B, editor. Handbook of family medicine. 4th ed. Cape Town: Oxford University Press, 2017; p. 334-359.

36. Rosenman R, Tennekoon V, Hill LG. Measuring bias in self-reported data. Int J Behav Healthc Res. 2011;2(4):320. https://doi.org/10.1504/IJBHR.2011.043414 